\title{
Prevalence of Coronary Heart Disease among Non-Smokers with Type 2 Diabetes Mellitus and Metabolic Syndrome Defined By NCEPATP 111 (National Cholesterol Education Programme Adult Treatment Panel 111)
}

\author{
Aye $\mathbf{M}^{1 *}$, Cabot $\mathrm{JSF}^{1}$ and Razak MSA ${ }^{2}$ \\ ${ }^{1}$ Department of Medicine, UniKL Royal College of Medicine, Perak, Malaysia \\ ${ }^{2}$ State Health Department, Ministry of Health, Perak, Malaysia
}

\begin{abstract}
Coronary Artery Disease (CAD) incidence varies according to certain risks; patients with pre-existing cardiovascular heart disease who later develop diabetes mellitus (DM) have the greatest risk, and non-diabetic patients with CAD, diabetic patients without CAD, and patients with metabolic syndrome (MetS) the next three high risk categories. Insulin resistance, a major feature in both DM and MetS probably causes atherogenic dyslipidaemia.
\end{abstract}

Objectives: (1) to determine the prevalence of MetS and DM in the study population, (2) to determine the prevalence of Coronary Artery Disease (CAD) in DM with MetS (DM+/MetS+), in DM alone (DM+/MetS-), MetS alone (Mets+/DM-) and in 'normal' group (DM-/MetS-), and (3) to determine the prevalence of MetS in DM patients.

Results: $62.1 \%$ of the study population had MetS, $44.7 \%$ had DM, $83.6 \%$ had both MetS and DM. $18.6 \%$ had CAD. CAD was seen in $25.2 \%$ of DM+/MetS+, $19.1 \%$ of MetS+/DM-, $14.3 \%$ of DM+/MetS-, and $11.6 \%$ of MetS-/DMpatients.

$\mathrm{DM}+/$ MetS+ group had the highest association with $\mathrm{CAD} O \mathrm{OR}=2.19, \mathrm{Cl}(1.43-3.35)$, DM-/MetS- group the lowest association $\mathrm{OR}=0.45, \mathrm{Cl}(0.27-0.73)$, and $\mathrm{DM}+/ \mathrm{MetS}-(\mathrm{OR}=0.69, \mathrm{Cl}(0.28-1.73)$ and MetS+/DM- $(\mathrm{OR}=0.94, \mathrm{Cl}(0.57$ 1.58) had no significant association with CAD.

Conclusion: Only DM+/MetS+ patients had a high risk of developing CAD. Risk of CAD in patients with MetS+/ DM- and DM+/MetS- was not statistically significant in multivariate analysis, while the group with neither, MS-/DM-, had the lowest risk of developing CAD.

Keywords: NNCEPATP111-defined metabolic syndrome; Diabetes mellitus; Cardiovascular heart disease

\section{Introduction}

MetS is characterized clinically by a clustering of factors; abnormal blood lipids (low HDL-C and high triglycerides), impaired glucose tolerance, elevated blood pressure, and abdominal obesity [1-4]. It is associated with five-fold risk of type $2 \mathrm{DM}$ and two-fold risk of cardiovascular disease $[5,6]$. DM developing with MetS, increases the macrovascular vascular disease contributed by MetS as both confer a common factor of insulin resistance, an important cause of atherogenic dyslipidaemia [7-11]. The exact contributions of the elements comprising the metabolic syndrome are not fully known; the most important factors being weight, genetics, endocrine disorders (such as polycystic ovary syndrome in women of reproductive age), aging, and sedentary lifestyle, (i.e., low physical activity and excess caloric intake) [12-16].

Many studies have shown $65-85 \%$ of individuals with DM have MetS [17]. There is a controversy of the importance of MetS in diabetics as a separate factor for cardiovascular risk. The few studies that have examined the combined effect of MetS and DM on CAD risk found increased prevalence of atherosclerotic CAD in patients with either DM or Mets alone, and in individuals with concurrent DM and MetS, a significant greater prevalence compared than either factor alone. However, a small prospective study and the United Kingdom Prospective Diabetes Study reported that in individuals with DM, those with MetS had a higher risk of CAD mortality, but those with DM without MetS did not [18-22].

Strategies to activate the peroxisome proliferator activated receptor- $\alpha$ (PPAR- $\alpha$ ) agonists such as exercise, omega 3 fatty acids and librates improve mitochondrial function and lipid metabolism in subjects with insulin resistance and prevent or reduce CAD and CAD related deaths have been attempted. However, even though early studies with fibrate therapy seemed to be beneficial, the ACCORD and others studies showed that combination therapy with statins and fibrates had no additional benefit over statins alone [23-30]. At best, whether combination therapy may be beneficial in patients with low HDL-C and high triglycerides remains unanswered. A very recent study even questions the benefit of weight loss in DM type 2 for reducing CAD leaving in question the best methods of reducing CAD in this group of patients [31].

We performed a retrospective study of the prevalence and association of CAD in a population with and without DM and MetS in a rural Malaysian out-patient setting (OPD).

\section{Materials and Methods}

A cross-sectional retrospective study was conducted from January 2, 2011 to November 30, 2012. Data was obtained from patients' medical records who attended medical specialist OPD and OPD patients in a district hospital in Perak, Malaysia. Sample size $(\mathrm{n}=398)$ was determined using the EpiInfo version 6 (CDC, Atlanta, GA, USA) for

*Corresponding author: Aye M, Department of Medicine, UniKL Royal College of Medicine, Perak, Malaysia, E-mail: mraaye@hotmail.com

Received July 16, 2013; Accepted August 16, 2013; Published August 19, 2013

Citation: Aye M, Cabot JSF, Razak MSA (2013) Prevalence of Coronary Heart Disease among Non-Smokers with Type 2 Diabetes Mellitus and Metabolic Syndrome Defined By NCEPATP 111 (National Cholesterol Education Programme Adult Treatment Panel 111). J Metabolic Synd 2: 123. doi:10.4172/21670943.1000123

Copyright: (c) 2013 Aye M, et al. This is an open-access article distributed under the terms of the Creative Commons Attribution License, which permits unrestricted use, distribution, and reproduction in any medium, provided the original author and source are credited. 
Citation: Aye M, Cabot JSF, Razak MSA (2013) Prevalence of Coronary Heart Disease among Non-Smokers with Type 2 Diabetes Mellitus and Metabolic Syndrome Defined By NCEPATP 111 (National Cholesterol Education Programme Adult Treatment Panel 111). J Metabolic Synd 2: 123. doi:10.4172/2167-0943.1000123

Page 2 of 5

population surveys. Samples were selected using randomised clustered systematic sampling with four patients selected every week. Inclusion criterion was age $\geq 20$ years, and exclusion criteria were patients with known pathological causes of obesity such as Cushing's and pseudoCushing's syndrome, known causes of dyslipidaemia such as chronic renal failure, nephrotic syndrome and hypothyroidism, HIV patients on antiviral drugs and smokers.

Body Mass Index (BMI) (body weight in $\mathrm{kg} / \mathrm{height}$ in $\mathrm{cm}^{2}$ ), Waist Circumference (WC) in cm. and Blood Pressure (BP) (mmHg) measurements (average of three readings one hour apart) were carried out by the same trained staff nurse. WC measurement was standardised at the midpoint between the lower costal cartilage and the highest point of the iliac crest with the patient exhaling completely. Samples for Fasting Plasma Glucose (FPG), serum Triglycerides (TG) and high density lipoprotein cholesterol (HDL-C) were taken in early morning after overnight fast. Definitions were high WC: $\geq 90 \mathrm{~cm}$ for males and $\geq 80 \mathrm{~cm}$ for females; hypertension: systolic $\mathrm{BP} \geq 130 \mathrm{mmHg}$ or diastolic $\mathrm{BP} \geq 85 \mathrm{mmHg}$; high fasting plasma glucose: FPG 5.6-6.99 $\mathrm{mmol} / \mathrm{L}$; diabetes mellitus: FPG $\geq 7 \mathrm{mmol} / \mathrm{L}$; low HDL-C: $<1.29 \mathrm{mmol} / \mathrm{L}$ in females and $<1.03 \mathrm{mmol} / \mathrm{L}$ in males; high TG: $\geq 1.7 \mathrm{mmol} / \mathrm{L}$ for both genders.

The research purpose was explained to each patients and the history and physical examination was done by the main investigator. Consent for blood tests from all the patients were obtained from all the patients.

The Harmonized NCEP criteria defined by lower cut-off points for waist circumference than the NCEP criteria was used to define MetS as more appropriate for South East Asians. CAD was defined by the patients' record: coronary angiography, angioplasty, CABG, symptoms of angina or unstable angina plus ECG changes, cardiac biomarkers with or without echocardiogram changes and response to coronary vasodilators. Patients were divided into two main groups: MetS+ and MetS-, and further sub-grouped according to DM: MetS+/DM+ and MetS+/DM-; and MetS-/DM+ and MetS-/DM- [32].

Statistical analyses were performed using the Statistical Package for the Social Sciences version 16 (SPSS Inc, Chicago, IL, USA). Student's $t$-test was used to compare the means. Pearson's chi-square test was used to identify the associations. $\mathrm{P}$ value less than 0.05 is defined as significant difference or association respectively.

\section{Results}

Prevalence of MetS was $83.6 \%$ in DM patients, $68.3 \%$ in patients with impaired fasting plasma glucose, and $34.6 \%$ in normal glucose tolerance group.

CAD prevalence was $11.6 \%$ in patients without either MetS or DM (MetS-/DM-); 14.3\% in MetS-/DM+; 19.1\% in MetS+/DM-, and 25.2\% in the Mets+/DM+ groups.

The difference in prevalence of MetS found in groups with $\mathrm{DM}+$, impaired FPG, and normal glucose tolerance was statistically significant $\left(\chi^{2}=86.9\right)$.

Table1 shows the frequency of demographic distribution of age, gender, ethnicity, prevalence of metabolic risk factors, MetS, DM, CAD, $\mathrm{DM}+/ \mathrm{MetS}+, \mathrm{MetS}+/ \mathrm{DM}-$, DM+/MetS- and DM-/MetS- in the study population.

Table 2 shows univariate analysis of age, BMI and WC cut-off, individual metabolic risk factors, $\mathrm{DM}$, metabolic syndrome, $\mathrm{DM}+1$ MS+, MS +/DM-, DM+/MS- and DM-/MS- and their association with CAD $(n=398)$.

\begin{tabular}{|c|c|c|c|}
\hline Variables & Number $(\%)$ & CAD $+(\mathbf{n}=\mathbf{7 4})$ & CAD $-(\mathbf{n = 3 2 4})$ \\
\hline Age & & & \\
\hline $20-29$ & $38(9.5)$ & $2(5.3)$ & $36(11)$ \\
\hline $30-39$ & $40(10.1)$ & $6(15)$ & $34(10.5)$ \\
\hline $40-49$ & $90(22.6)$ & $18(20)$ & $72(22.2)$ \\
\hline $50-59$ & $127(31.9)$ & $28(22)$ & $99(30.6)$ \\
\hline$\geq 60$ & $103(25.9)$ & $20(19.4)$ & $83(25.6)$ \\
\hline Gender & & & \\
\hline Female & $204(51.3)$ & $38(18.6)$ & $166(18.4)$ \\
\hline Male & $194(48.7)$ & $38(18.6)$ & $158(18.4)$ \\
\hline Ethnicity & & & \\
\hline Malay & $162(40.7)$ & $38(17.3)$ & $124(82.7)$ \\
\hline Indian & $144(36.2)$ & $28(19.4)$ & $116(80.6)$ \\
\hline Chinese & $92(23.1)$ & $19(19.6)$ & $74(80.4)$ \\
\hline
\end{tabular}

CAD showed no association with either gender or ethnicity.

Table 1: Distribution of demographic factors in the study population and association between CAD positive and negative subjects $(n=398)$.

\begin{tabular}{|c|c|c|c|c|}
\hline Variables & Number (\%) & $\begin{array}{c}\text { CAD } \\
(n=74)\end{array}$ & $\begin{array}{l}\text { No CAD } \\
(n=324)\end{array}$ & $P$ value, $O R,(95 \% \mathrm{Cl})$ \\
\hline Age cut-off ${ }^{*}$ & $315(85.2)$ & $65(20.6)$ & $250(79.4)$ & $0.04,2.14(1.02-4.50)$ \\
\hline BMI cut-off * & $209(52.5)$ & $47(22.5)$ & $162(77.5)$ & $0.97,1.60(0.96-2.68)$ \\
\hline WC cut-off * & 173 & $35(20.2)$ & $138(79.8)$ & $0.62,1.44(0.85-2.44)$ \\
\hline \multicolumn{5}{|l|}{ MetS Risks } \\
\hline Hypertension & $239(60.1)$ & $52(21.8)$ & $187(78.2)$ & $0.04,1.73(1.02-2.99)$ \\
\hline Raised FPG & $237(59.5)$ & $53(22.4)$ & $184(77.6)$ & $0.01,1.92(1.11-3.33)$ \\
\hline Low HDL-C & $224(56.3)$ & $42(18.8)$ & $182(81.2)$ & $0.18,1.02(0.62-1.71)$ \\
\hline High TG & $161(40.5)$ & $35(21.7)$ & $126(78.3)$ & $0.18,1.41(0.85-2.34)$ \\
\hline High WC & $268(67.3)$ & $54(20.1)$ & $214(79.9)$ & $0.25,1.39(0.79-2.44)$ \\
\hline DM & $161(40.5)$ & $38(23.6)$ & $123(76.4)$ & $0.03,1.73(1.04-2.87)$ \\
\hline MetS & $247(62.1)$ & $58(23.5)$ & $189(76.5)$ & $0.00,2.25(1.41-3.59)$ \\
\hline $\mathrm{DM}+/ \mathrm{MS}+$ & $151(37.9)$ & $38(25.2)$ & $113(74.8)$ & $0.00,2.19(1.43-3.35)$ \\
\hline MS+/DM- & $93(23.6)$ & $18(19.1)$ & $73(80.9)$ & $0.87,0.94(0.57-1.58)$ \\
\hline $\mathrm{DM}+/ \mathrm{MS}-$ & $28(7)$ & $4(14.3)$ & $24(85.7)$ & $0.53,0.69(0.28-1.73)$ \\
\hline DM-/MS- & $126(31.6)$ & $15(11.6)$ & $111(78.4)$ & $0.00,0.45(0.27-0.73)$ \\
\hline
\end{tabular}

Age cut-off $=42.5$ years old, BMl cut-off $=26.5 \mathrm{~kg} / \mathrm{cm}^{2}$, WC cut-off $=94.5 \mathrm{~cm}$ for female and $96 \mathrm{~cm}$ for males, $p$ value $<0.05$ is significant

Table 2: Shows univariate analysis of individual components of MetS, full MetS and $\mathrm{DM}$ in association with CAD.

\begin{tabular}{|l|c|c|}
\hline Variables & p value & OR $\mathbf{( 9 5 \% ~ C l ) ~}$ \\
\hline MetS & 0.04 & $2.28(1.04-5.03)$ \\
\hline Hypertension & 0.92 & $0.97(0.48-1.96$ \\
\hline Raised fasting blood Glucose & 0.52 & $1.23(0.65-2.25)$ \\
\hline High triglycerides & 0.84 & $0.94(0.53-1.68)$ \\
\hline Low HDL-C & 0.25 & $0.72(0.41-1.27)$ \\
\hline High WC & 0.45 & $0.76(0.37-1.55)$ \\
\hline
\end{tabular}

Table 3: Multivariate logistic regression analysis of association of risk factors of MetS and MetS with CAD.

Prevalence of CAD with MetS was higher than DM. Prevalence of CAD overall was $18.6 \%$. Patients with $\mathrm{DM}+/$ MetS+ had the highest while those with DM+/MetS- and those with neither, MetS-/DM-, the lowest prevalence of CAD respectively. Patients with MetS + / DM- had an intermediate prevalence for CAD. Patients with Mets+/DM+, older age, hypertension, elevated FPG, MetS, DM and DM+/MetS+ were significantly associated with CAD by univariate analysis.

Table 3 shows CAD by multiple regression analysis. Only MetS+ 
Citation: Aye M, Cabot JSF, Razak MSA (2013) Prevalence of Coronary Heart Disease among Non-Smokers with Type 2 Diabetes Mellitus and Metabolic Syndrome Defined By NCEPATP 111 (National Cholesterol Education Programme Adult Treatment Panel 111). J Metabolic Synd 2: 123. doi:10.4172/2167-0943.1000123

Page 3 of 5

was associated with CAD, indicating the combination of individual risk factors for MetS is more significant than any individual risk factors of MetS for developing CAD.

The analysis of association of CAD with DM, MetS and age by multiple regression analysis, showed only MetS is positive (Table 4).

\section{Discussion}

Our study showing the significant association of $\mathrm{DM}+/ \mathrm{MetS}+$, but not Mets+/DM- or DM+/MetS- with CAD, (Table 2) is consistent with others [17-21]. This may be due to enhancement of macro and micro vascular diseases of MetS by hyperglycaemia of diabetes.

By univariate analysis, the prevalence of CAD in Mets+/DM- is

\begin{tabular}{|l|c|c|}
\hline Variables & p value & OR $(\mathbf{9 5} \% \mathbf{C l})$ \\
\hline MetS & 0.02 & $2.05(1.09-3.85)$ \\
\hline DM & 0.44 & $1.24(0.72-2.16)$ \\
\hline Age $\geq 42.5$ & 0.15 & $1.74(0.81-3.73)$ \\
\hline
\end{tabular}

Table 4: Multivariate logistic regression analysis of association of MetS, DM and Age 43 and above with CAD. intermediate between DM overall and DM without MetS. This finding is consistent with finding of others [22,33] which demonstrated an increased prevalence, incidence, and risk of CAD mortality in subjects with metabolic syndrome, regardless of whether or not they had type 2 diabetes. This is also supported by studies from Quebec and Finland that showed even without hyperglycaemia, elevated levels of insulin (i.e., insulin resistance), were associated with risk of CAD [34,35].

While our study showing a higher prevalence of CAD in DM+/MetSin univariate analysis than the cohort with neither is consistent with other reports, this was not significant by multivariate analysis [17-21].

Studies have shown that even small increases in fasting or postprandial glucose values (including impaired glucose tolerance or impaired fasting glucose) impart an increased risk for cardiovascular morbidity and mortality [36-41]. While again seen in our study by univariate analysis; with $11.4 \%$ (normal FPG), 14.5\% (impaired FPG) and $22.9 \%(\mathrm{DM})$ patient groups having CAD respectively, this was not supported by multivariate analysis. Thus it appears; that FPG, if not in the DM range, may not be significantly associated with CAD as in our study MetS without DM was not significantly associated with CAD as opposed to DM+/Mets+.

\begin{tabular}{|c|c|c|c|c|c|c|c|c|}
\hline & & with CAD & without CAD & P-value & & with CAD & without CAD & P-value \\
\hline \multirow{4}{*}{ Age } & $\mathrm{DM}+/ \mathrm{MS}+$ & $\begin{array}{l}(n=38) \\
53.5 \pm 11.6\end{array}$ & $\begin{array}{l}(n=113) \\
53.6 \pm 11.1\end{array}$ & 0.91 & \multirow{4}{*}{ FPG } & $\begin{array}{l}(n=38) \\
9.33 \pm 2.83\end{array}$ & $\begin{array}{l}(n=113) \\
9.13 \pm 2.51\end{array}$ & 0.69 \\
\hline & DM+/MetS- & $\begin{array}{l}(n=4) \\
52.1 \pm 12.9\end{array}$ & $\begin{array}{l}(n=24) \\
56.7 \pm 10.0\end{array}$ & 0.30 & & $\begin{array}{l}(n=4) \\
9.25 \pm 1.88\end{array}$ & $\begin{array}{l}(n=24) \\
9.39 \pm 3.39\end{array}$ & 0.67 \\
\hline & MetS+/DM- & $\begin{array}{l}(n=18) \\
50.2 \pm 13.9\end{array}$ & $\begin{array}{l}(n=60) \\
51.3 \pm 13.5\end{array}$ & 0.25 & & $\begin{array}{l}(n=18) \\
5.17 \pm 0.73\end{array}$ & $\begin{array}{l}(n=60) \\
5.36 \pm 0.67\end{array}$ & 0.32 \\
\hline & MetS-/DM- & $\begin{array}{l}(n=14) \\
44 \pm 17.7\end{array}$ & $\begin{array}{l}(n=127) \\
45.5 \pm 16.5\end{array}$ & 0.49 & & $\begin{array}{l}(n=14) \\
4.69 \pm 0.71\end{array}$ & $\begin{array}{l}(n=127) \\
4.84 \pm 0.53\end{array}$ & 0.44 \\
\hline \multirow{4}{*}{ BMI } & $\mathrm{DM}+/ \mathrm{MS}+$ & $\begin{array}{l}(n=38) \\
30.1 \pm 7.16\end{array}$ & $\begin{array}{l}(n=113) \\
30.2 \pm 7.04\end{array}$ & 0.78 & \multirow{4}{*}{ Triglycerides } & $\begin{array}{l}(n=38) \\
2.24 \pm 2.03\end{array}$ & $\begin{array}{l}(n=113) \\
2.14 \pm 1.74\end{array}$ & 0.46 \\
\hline & DM+/MetS- & $\begin{array}{l}(n=4) \\
23.3 \pm 3.23\end{array}$ & $\begin{array}{l}(n=24) \\
23.5 \pm 3.70\end{array}$ & 0.49 & & $\begin{array}{l}(n=4) \\
1.29 \pm 0.43\end{array}$ & $\begin{array}{l}(n=24) \\
1.35 \pm 0.42\end{array}$ & 0.19 \\
\hline & MetS+/DM- & $\begin{array}{l}(n=18) \\
28.5 \pm 5.10\end{array}$ & $\begin{array}{l}(n=60) \\
29.3 \pm 5.50\end{array}$ & 0.13 & & $\begin{array}{l}(n=18) \\
2.12 \pm 1.15\end{array}$ & $\begin{array}{l}(n=60) \\
1.99 \pm 0.98\end{array}$ & 0.48 \\
\hline & MetS-/DM- & $\begin{array}{l}(n=14) \\
25.0 \pm 6.83\end{array}$ & $\begin{array}{l}(n=127) \\
25.1 \pm 7.12\end{array}$ & 0.88 & & $\begin{array}{l}(n=14) \\
1.20 \pm 0.55\end{array}$ & $\begin{array}{l}(n=127) \\
1.37 \pm 0.60\end{array}$ & 0.48 \\
\hline \multirow{4}{*}{ WC } & $\mathrm{DM}+/ \mathrm{MS}+$ & $\begin{array}{l}(n=38) \\
99.1 \pm 12.6\end{array}$ & $\begin{array}{l}(n=113) \\
98.4 \pm 11.4\end{array}$ & 0.63 & \multirow{4}{*}{ HDL-C } & $\begin{array}{l}(n=38) \\
1.04 \pm 0.34\end{array}$ & $\begin{array}{l}(n=113) \\
1.03 \pm 0.35\end{array}$ & 0.27 \\
\hline & DM+/MetS- & $\begin{array}{l}(n=4) \\
84.1 \pm 11.5\end{array}$ & $\begin{array}{l}(n=24) \\
83.3 \pm 12.5\end{array}$ & 0.09 & & $\begin{array}{l}n=4 \\
1.32 \pm 0.49\end{array}$ & $\begin{array}{l}(n=24) \\
1.27 \pm 0.45\end{array}$ & 0.62 \\
\hline & MetS+/DM- & $\begin{array}{l}(n=18) \\
98.1 \pm 10.4\end{array}$ & $\begin{array}{l}(n=60) \\
98.3 \pm 10.4\end{array}$ & 0.47 & & $\begin{array}{l}(n=18) \\
1.03 \pm 0.31\end{array}$ & $\begin{array}{l}(n=60) \\
1.02 \pm 0.31\end{array}$ & 0.80 \\
\hline & MetS-/DM- & $\begin{array}{l}(n=14) \\
83.7 \pm 14.1\end{array}$ & $\begin{array}{l}(n=127) \\
83.5 \pm 14.9\end{array}$ & 0.88 & & $\begin{array}{l}(n=14) \\
1.34 \pm 0.57\end{array}$ & $\begin{array}{l}(n=127) \\
1.37 \pm 0.60\end{array}$ & 0.69 \\
\hline \multirow{4}{*}{ Systolic BP } & $\mathrm{DM}+/ \mathrm{MS}+$ & $\begin{array}{l}(n=38) \\
143 \pm 17.2\end{array}$ & $\begin{array}{l}(n=113) \\
143 \pm 16.40\end{array}$ & 0.58 & \multirow{4}{*}{ Total CHO } & $\begin{array}{l}(n=38) \\
5.18 \pm 1.42\end{array}$ & $\begin{array}{l}(n=113) \\
5.14 \pm 1.46\end{array}$ & 0.05 \\
\hline & DM+/MetS- & $\begin{array}{l}(n=4) \\
112 \pm 15.9\end{array}$ & $\begin{array}{l}(n=24) \\
120 \pm 13.8\end{array}$ & 0.71 & & $\begin{array}{l}(n=4) \\
5.32 \pm 1.89\end{array}$ & $\begin{array}{l}(n=24) \\
5.44 \pm 1.65\end{array}$ & 0.55 \\
\hline & MetS+/DM- & $\begin{array}{l}(n=18) \\
142 \pm 18.3\end{array}$ & $\begin{array}{l}(n=60) \\
142 \pm 18.0\end{array}$ & 0.91 & & $\begin{array}{l}(n=18) \\
5.13 \pm 1.53\end{array}$ & $\begin{array}{l}(n=60) \\
5.18 \pm 1.55\end{array}$ & 0.43 \\
\hline & MetS-/DM- & $\begin{array}{l}(n=14) \\
122 \pm 17.8\end{array}$ & $\begin{array}{l}(n=127) \\
123 \pm 17.6\end{array}$ & 0.96 & & $\begin{array}{l}(n=14) \\
4.74 \pm 1.35\end{array}$ & $\begin{array}{l}(n=127) \\
4.84 \pm 1.38\end{array}$ & 0.15 \\
\hline \multirow{4}{*}{ Diastolic BP } & $\mathrm{DM}+/ \mathrm{MS}+$ & $\begin{array}{l}(n=38) \\
85.7 \pm 10.4\end{array}$ & $\begin{array}{l}(n=113) \\
85.6 \pm 10.3\end{array}$ & 0.79 & \multirow{4}{*}{ LDL-C } & $\begin{array}{l}(n=38) \\
3.37 \pm 1.50\end{array}$ & $\begin{array}{l}(n=113) \\
3.43 \pm 1.46\end{array}$ & 0.92 \\
\hline & DM+/MetS- & $\begin{array}{l}(n=4) \\
77.7 \pm 10.7\end{array}$ & $\begin{array}{l}(n=24) \\
78.1 \pm 10.2\end{array}$ & 0.51 & & $\begin{array}{l}(n=4) \\
3.20 \pm 1.21\end{array}$ & $\begin{array}{l}(n=24) \\
3.09 \pm 0.86\end{array}$ & 0.59 \\
\hline & MetS+/DM- & $\begin{array}{l}(n=18) \\
86.0 \pm 10.1\end{array}$ & $\begin{array}{l}(n=60) \\
85.0 \pm 10.0\end{array}$ & 0.36 & & $\begin{array}{l}(n=18) \\
3.17 \pm 1.13\end{array}$ & $\begin{array}{l}(n=60) \\
3.28 \pm 1.11\end{array}$ & 0.12 \\
\hline & MetS-/DM- & $\begin{array}{l}(n=14) \\
77.0 \pm 10.4\end{array}$ & $\begin{array}{l}(n=127) \\
78.4 \pm 9.32\end{array}$ & 0.33 & & $\begin{array}{l}(n=14) \\
3.18 \pm 1.12\end{array}$ & $\begin{array}{l}(n=127) \\
3.28 \pm 1.15\end{array}$ & 0.16 \\
\hline
\end{tabular}

Only the DM+/MetS+ with CAD is found to be different from that of CAD negative by having $p$ value 0.05 although it is not less than 0.05

Table 5: Mean of age, BMI, metabolic risk factors, total cholesterol and low density lipoprotein in subjects with DM+/MetS+, MetS+/DM- , DM+/MetS- and MetS -/DM- with and without_ CAD. 
Citation: Aye M, Cabot JSF, Razak MSA (2013) Prevalence of Coronary Heart Disease among Non-Smokers with Type 2 Diabetes Mellitus and Metabolic Syndrome Defined By NCEPATP 111 (National Cholesterol Education Programme Adult Treatment Panel 111). J Metabolic Synd 2: 123. doi:10.4172/2167-0943.1000123

Page 4 of 5

Our study, which in agreement with others, found no significant association of MetS+/DM- and DM+/MetS- with CAD, is also consistent with recent findings that patients with obesity alone, without associated morbid conditions, do not appear to have an increased incidence of CAD [42].

Our finding of association of CAD prevalence with MetS (Tables $2-4)$ is also consistent with other studies [5,32,43,44]. Our study is unable to answer whether the presence of more risk elements of MetS contribute to a higher risk of CAD [16]. In multivariate analysis only MetS is significantly associated with CAD although elevated FPG and hypertension are significantly associated with CAD in univariate analysis (Table 2). It indicates that perhaps elevated FPG and hypertension are the more important driving factors for CAD risk in MetS. While not in agreement with some studies [18] where low HDL-C was the most predictive risk of CAD, our finding support yet other studies as well as the recent analysis of metabolic syndrome in the Pressioni Arteriose Monitorate E Loro Associazioni (PAMELA) study $[45,46]$ that BP elevation is the most common component $(95.4 \%)$ of the metabolic syndrome. The contribution of metabolic syndrome components to CAD and all-cause mortality was mainly related to $\mathrm{BP}$ and glucose abnormalities. It also supports that MetS, irrespective of its definition, is an independent clinical indicator of macro and micro vascular complications in diabetes $[21,22,47,48]$. Therefore, metabolic syndrome appears not to be just a pre-diabetes syndrome, but by itself, a very high-risk state [43].

We showed that LDL-C levels were comparable in CAD and nonCAD groups (Table 5 a-e), (although many of our patients were on statins), CAD may be caused by triglycerides rich arthrogenic lipids, a component of LDL-C which was not measured. It is supported by our finding in table 5 that TG alone is noted to be in association with CAD. Our findings support the Heart Protection Study that asserted treatment of CAD with statins alone is insufficient therapy of CAD [25].

45.4 percent and 10 percent of our study cohort were on statins and fibrates respectively. Our finding are thus in agreement with other studies that showed raising HDL-C by drug means does not improve risk of CAD above lowering of LDL-C with statins [31]. However, this may depend on which component of the MetS is the most dominant. If it is low HDL-C, combined therapy might have additional benefit, but if, for example, it is hypertension and elevated FPG, combined therapy may not have any additional benefit.

This study has several limitations. Firstly, 54\% of patients enrolled

\begin{tabular}{|l|c|c|c|}
\hline \multirow{2}{*}{ Variable } & CHD + & $\begin{array}{c}\text { CHD - } \\
\text { Mean } \pm \text { SD }\end{array}$ & \multirow{2}{*}{ p-value } \\
\cline { 2 - 3 } & $53.5 \pm 11.6$ & $53.6 \pm 11.1$ & .09 \\
\hline Age & $30.1 \pm 7.16$ & $30.2 \pm 7.04$ & .45 \\
\hline BMI & $99.1 \pm 12.6$ & $98.4 \pm 11.4$ & .15 \\
\hline WC & $143 \pm 17.2$ & $143 \pm 16.4$ & .26 \\
\hline Systolic BP & $85.7 \pm 10.4$ & $85.6 \pm 10.3$ & .75 \\
\hline Diastolic BP & $9.33 \pm 2.83$ & $9.13 \pm 2.51$ & .08 \\
\hline FPG & $2.24 \pm 2.03$ & $2.14 \pm 1.74$ & .04 \\
\hline Triglycerides & $1.04 \pm 0.34$ & $1.03 \pm 0.35$ & .43 \\
\hline HDL-C & $5.18 \pm 1.42$ & $5.14 \pm 1.46$ & .31 \\
\hline Total CHO & $3.37 \pm 1.50$ & $3.43 \pm 1.46$ & .33 \\
\hline LDL-C & & \\
\hline
\end{tabular}

Triglycerides only is noted to be significantly different among CAD positive and negative

Table 6: Mean of age, BMI, metabolic risk factors, total cholesterol and low density lipoprotein in subjects with $\mathrm{DM}+/ \mathrm{MetS}+$ in the whole study population with and without CAD. were already on treatment for hypertension, diabetes mellitus and hypercholesterolemia. We tried to overcome these by obtaining the necessary sample size and by using pre-therapy data. Secondly, most of the patients in this study already had MetS with DM simultaneously at presentation. The cross-sectional study employed here is unable to answer whether DM+/MetS- or DM-/MetS+ progressing to $\mathrm{DM}+/$ MetS+ is more predisposing to CAD (Table 6), for which a prospective study of isolated DM and MetS is necessary. Finally, as this was a hospital-based study, the findings do not represent the whole Malaysian population or the local community. Further larger population-based studies are necessary to support our findings.

In conclusion, our study showed that only DM patients with MetS+ are significantly associated with CAD morbidity.

\section{Acknowledgement}

We would like to acknowledge research and ethical committee of the institution (UniKLRCMP) for allowing to study and for the grant and Director of Ministry of Health of Malaysia for allowing to conduct the study.

\section{References}

1. Expert Panel on Detection, Evaluation, and Treatment of High Blood Cholesterol in Adults (2001) Executive Summary of The Third Report of The National Cholesterol Education Program (NCEP) Expert Panel on Detection, Evaluation, And Treatment of High Blood Cholesterol In Adults (Adult Treatment Panel III). JAMA 285: 2486-2497.

2. Alberti KG, Zimmet PZ (1998) Definition, diagnosis and classification of diabetes mellitus and its complications. Part 1: diagnosis and classification of diabetes mellitus provisional report of a WHO consultation. Diabet Med 15: 539-553.

3. American Diabetes Association (2006) Standards of medical care in diabetes--2006. Diabetes Care 29 Suppl 1: S4-42.

4. Grundy SM, Brewer HB Jr, Cleeman JI, Smith SC Jr, Lenfant C; American Heart Association; National Heart, et al. (2004) Definition of metabolic syndrome: Report of the National Heart, Lung, and Blood Institute/American Heart Association conference on scientific issues related to definition. Circulation 109: 433-438.

5. Zimmet P, Magliano D, Matsuzawa Y, Alberti G, Shaw J (2005) The metabolic syndrome: a global public health problem and a new definition. J Atheroscler Thromb 12: 295-300.

6. Najarian RM, Sullivan LM, Kannel WB, Wilson PW, D'Agostino RB, et al. (2006) Metabolic syndrome compared with type 2 diabetes mellitus as a risk factor for stroke: the Framingham Offspring Study. Arch Intern Med 166: 106-111.

7. Lamarche B, Tchernof A, Mauriège P, Cantin B, Dagenais GR, et al. (1998) Fasting insulin and apolipoprotein $B$ levels and low-density lipoprotein particle size as risk factors for ischemic heart disease. JAMA 279: 1955-1961.

8. World Health Organization (1992) Definition, diagnosis and classification of diabetes mellitus. WHO/NCD/NCS/99.2. Geneva, Switzerland: Department of non- communicable Disease Surveillance, World Health Organization, 32-3.

9. Reaven GM (1988) Banting lecture 1988. Role of insulin resistance in human disease. Diabetes 37: 1595-1607.

10. Balkau B, Charles MA (1999) Comment on the provisional report from the WHO consultation. European Group for the Study of Insulin Resistance (EGIR) Diabet Med 16: 442-443.

11. Koehler C, Ott P, Benke I, Hanefeld M; DIG Study Group (2007) Comparison of the prevalence of the metabolic syndrome by WHO, AHA/NHLBI, and IDF definitions in a German population with type 2 diabetes: the Diabetes in Germany (DIG) Study. Horm Metab Res 39: 632-635.

12. Pollex RL, Hegele RA (2006) Genetic determinants of the metabolic syndrome. Nat Clin Pract Cardiovasc Med 3: 482-489.

13. Poulsen P, Vaag A, Kyvik K, Beck-Nielsen H (2001) Genetic versus environmental aetiology of the metabolic syndrome among male and female twins. Diabetologia 44: 537-543.

14. Groop L (2000) Genetics of the metabolic syndrome. Br J Nutr 83 Suppl 1 S39-48. 
Citation: Aye M, Cabot JSF, Razak MSA (2013) Prevalence of Coronary Heart Disease among Non-Smokers with Type 2 Diabetes Mellitus and Metabolic Syndrome Defined By NCEPATP 111 (National Cholesterol Education Programme Adult Treatment Panel 111). J Metabolic Synd 2: 123. doi:10.4172/2167-0943.1000123

Page 5 of 5

15. Bouchard G (1995) Genetics and the metabolic syndrome. Int J Obes 19: 52 59.

16. Alshkri M, Elmehdawi R (2008) Metabolic Syndrome among Type-2 Diabetic Patients in Benghazi-Libya: A pilot study. Libyan J Med 3: 177-180.

17. Alexander CM, Landsman PB, Teutsch SM, Haffner SM (2003) NCEP-defined metabolic syndrome, diabetes, and prevalence of coronary heart disease among NHANES III participants age 50 years and older. Diabetes 52: 12101214.

18. Hunt KJ, Resendez RG, Williams K, Haffner SM, Stern MP; San Antonio Heart Study (2004) National Cholesterol Education Program versus World Health Organization metabolic syndrome in relation to all-cause and cardiovascular mortality in the San Antonio Heart Study. Circulation 110: 1251-1257.

19. Church TS, Thompson AM, Katzmarzyk PT, Sui X, Johannsen N, et al. (2009) Metabolic syndrome and diabetes, alone and in combination, as predictors of cardiovascular disease mortality among men. Diabetes Care 32: 1289-1294.

20. Mottillo S, Filion KB, Genest J, Joseph L, Pilote L, et al. (2010) The metabolic syndrome and cardiovascular risk a systematic review and meta-analysis. J Am Coll Cardiol 56: 1113-1132.

21. Hu G, Qiao Q, Tuomilehto J, Balkau B, Borch-Johnsen K, et al. (2004) Prevalence of the metabolic syndrome and its relation to all-cause and cardiovascular mortality in nondiabetic European men and women. Arch Intern Med 164: 1066-1076.

22. Cull CA, Jensen CC, Retnakaran R, Holman RR (2007) Impact of the metabolic syndrome on macrovascular and microvascular outcomes in type 2 diabetes mellitus: United Kingdom Prospective Diabetes Study 78. Circulation 116: 2119-2126.

23. Keech A, Simes RJ, Barter P, Best J, Scott R, et al. (2005) Effects of longterm fenofibrate therapy on cardiovascular events in 9795 people with type 2 diabetes mellitus (the FIELD study): randomised controlled trial. Lancet 366 : 1849-1861.

24. Davidson $\mathrm{MH}$, Yannicelli HD (2006) New concepts in dyslipidemia in the metabolic syndrome and diabetes. Metab Syndr Relat Disord 4: 299-314.

25. Look AHEAD Research Group, Wing RR, Bolin P, Brancati FL, Bray GA, et al. (2013) Cardiovascular effects of intensive lifestyle intervention in type 2 diabetes. N Engl J Med 369: 145-154.

26. Goldfine AB, Kaul S, Hiatt WR (2011) Fibrates in the treatment of dyslipidemias-time for a reassessment. N Engl J Med 365: 481-484.

27. Després JP, Lemieux I, Dagenais GR, Cantin B, Lamarche B (2000) $\mathrm{HDL}$-cholesterol as a marker of coronary heart disease risk: the Québec cardiovascular study. Atherosclerosis 153: 263-272.

28. ACCORD Study Group, Gerstein HC, Miller ME, Genuth S, Ismail-Beigi F, et al. (2011) Long-term effects of intensive glucose lowering on cardiovascular outcomes. N Engl J Med 364: 818-828.

29. NIH News (2011) NIH stops clinical trial on combination cholesterol treatment NHLBI Communications Office 301-496-423.

30. Gerstein HC (2013) Do lifestyle changes reduce serious outcomes in diabetes? N Engl J Med 369: 189-190.

31. Alberti KGMM, Robert HE, Scott M (2009) Harmonizing the Metabolic Syndrome; American Heart Association; World Heart Federation; International Atherosclerosis Society; and International Association for the Study of Obesity Circulation 120: 1640-1645.

32. Lakka HM, Laaksonen DE, Lakka TA, Niskanen LK, Kumpusalo E, et al. (2002) The metabolic syndrome and total and cardiovascular disease mortality in middle-aged men. JAMA 288: 2709-2716.

33. Després JP, Lamarche B, Mauriège P, Cantin B, Dagenais GR, et al. (1996) Hyperinsulinemia as an independent risk factor for ischemic heart disease. $N$ Engl J Med 334: 952-957.
34. Pyörälä M, Miettinen $\mathrm{H}$, Laakso M, Pyörälä K (2000) Plasma insulin and altcause, cardiovascular, and noncardiovascular mortality: the 22-year follow-up results of the Helsinki Policemen Study. Diabetes Care 23: 1097-1102.

35. Gerstein HC (1999) Is glucose a continuous risk factor for cardiovascula mortality? Diabetes Care 22: 659-660.

36. DECODE Study Group, the European Diabetes Epidemiology Group. (2001) Glucose tolerance and cardiovascular mortality: comparison of fasting and 2-hour diagnostic criteria. Arch Intern Med 161: 397-405

37. [No authors listed] (1999) Glucose tolerance and mortality: comparison of WHO and American Diabetes Association diagnostic criteria. The DECODE study group. European Diabetes Epidemiology Group. Diabetes Epidemiology: Collaborative analysis Of Diagnostic criteria in Europe. Lancet 354: 617-621.

38. Haffner SM (1997) Impaired glucose tolerance--is it relevant for cardiovascular disease? Diabetologia 40 Suppl 2: S138-140.

39. Balkau B, Shipley M, Jarrett RJ, Pyorala K, Pyorala M, et al. (1998) High blood glucose concentration is a risk factor for mortality in middle-aged non-diabetic men: 20-year follow-up in the Whitehall Study, the Paris Prospective Study, and the Helsinki Policeman Study. Diabetes Care 21: 360-367.

40. Meigs JB, Nathan DM, Wilson PW, Cupples LA, Singer DE (1998) Metabolic risk factors worsen continuously across the spectrum of nondiabetic glucose tolerance. The Framingham Offspring Study. Ann Intern Med 128: 524-533.

41. Isomaa B, Almgren P, Tuomi T, Forsén B, Lahti K, et al. (2001) Cardiovascular morbidity and mortality associated with the metabolic syndrome. Diabetes Care 24: 683-689.

42. Meigs JB, Wilson PW, Fox CS, Vasan RS, Nathan DM, et al. (2006) Body mass index, metabolic syndrome, and risk of type 2 diabetes or cardiovascula disease. J Clin Endocrinol Metab 91: 2906-2912.

43. Gimeno Orna JA, Lou Arnal LM, Molinero Herguedas E, Boned Julián B Portilla Córdoba DP (2004) [Metabolic syndrome as a cardiovascular risk factor in patients with type 2 diabetes]. Rev Esp Cardiol 57: 507-513.

44. Malik S, Wong ND, Franklin SS, Kamath TV, L'Italien GJ, et al. (2004) Impact of the metabolic syndrome on mortality from coronary heart disease, cardiovascular disease, and all causes in United States adults. Circulation 110 1245-1250.

45. Mancia G, Bombelli M, Corrao G, Facchetti R, Madotto F, et al. (2007) Metabolic syndrome in the Pressioni Arteriose Monitorate E Loro Associazioni (PAMELA) study: daily life blood pressure, cardiac damage, and prognosis. Hypertension 49: $40-47$.

46. Liu J, Grundy SM, Wang W, Smith SC Jr, Vega GL, et al. (2007) Ten-year risk of cardiovascular incidence related to diabetes, prediabetes, and the metabolic syndrome. Am Heart J 153: 552-558.

47. Metascreen Writing Committee, Bonadonna R, Cucinotta D, Fedele D, Riccard G, et al. (2006) The metabolic syndrome is a risk indicator of microvascula and macrovascular complications in diabetes: results from Metascreen, a multicenter diabetes clinic-based survey. Diabetes Care 29: 2701-2707.

48. Wong J, Molyneaux L, Constantino MI, Twigg SM, Yue DK (2006) The metabolic syndrome in type 2 diabetes: When does it matter? Diabetes Obes Metab 8 : 690-697. 